\title{
Phylogeography, Salinity Adaptations and Metabolic Potential of the Candidate Division KB1 Bacteria Based on a Partial Single Cell Genome
}

\author{
Lisa M. Nigro *, Andrew S. Hyde, Barbara J. MacGregor and Andreas Teske \\ Department of Marine Sciences, University of North Carolina at Chapel Hill, Chapel Hill, NC, USA
}

\section{OPEN ACCESS}

Edited by:

Brian D. Lanoil,

University of Alberta, Canada

Reviewed by:

Ronald Oremland,

United States Geological Survey, USA

Dimitry Y. Sorokin,

Winogradsky Institute of Microbiology, Russian Academy of Sciences, Russia

*Correspondence:

Lisa M. Nigro

Inigro@uwf.edu

tPresent address: Lisa M. Nigro,

Center for Environmental Diagnostics and Bioremediation, Hal Marcus

College of Science and Engineering, University of West Florida,

Pensacola, FL, USA

Specialty section:

This article was submitted to

Extreme Microbiology,

a section of the journa

Frontiers in Microbiology

Received: 06 June 2016 Accepted: 02 August 2016 Published: 22 August 2016

Citation: Nigro LM, Hyde AS, MacGregor BJ and Teske A (2016) Phylogeography,

Salinity Adaptations and Metabolic

Potential of the Candidate Division KB1 Bacteria Based on a Partial Single Cell Genome.

Front. Microbiol. 7:1266. doi: 10.3389/fmicb.2016.01266
Deep-sea hypersaline anoxic basins and other hypersaline environments contain abundant and diverse microbial life that has adapted to these extreme conditions. The bacterial Candidate Division KB1 represents one of several uncultured groups that have been consistently observed in hypersaline microbial diversity studies. Here we report the phylogeography of KB1, its phylogenetic relationships to Candidate Division OP1 Bacteria, and its potential metabolic and osmotic stress adaptations based on a partial single cell amplified genome of KB1 from Orca Basin, the largest hypersaline seafloor brine basin in the Gulf of Mexico. Our results are consistent with the hypothesis previously developed based on ${ }^{14} \mathrm{C}$ incorporation experiments with mixed-species enrichments from Mediterranean seafloor brines - that KB1 has adapted its proteins to elevated intracellular salinity, but at the same time KB1 apparently imports glycine betaine; this compatible solute is potentially not limited to osmoregulation but could also serve as a carbon and energy source.

Keywords: Candidate Division KB1, Orca Basin, phylogeography, genome, hypersaline

\section{INTRODUCTION}

Hypersaline environments are abundant on Earth (e.g., Boetius and Joye, 2009) and include hypersaline lakes, such as the Dead Sea or the Great Salt Lake; evaporative lagoons; salterns; and hypersaline marine basins where salt deposits dissolve into deep-sea water and create distinct "lakes" of high-density brines on the seafloor of the Red Sea, Mediterranean Sea and Gulf of Mexico. These deep-sea hypersaline anoxic basins (DHABs) have been the recent focus of molecular microbial investigation (Eder et al., 2001; van der Wielen, 2005; La Cono et al., 2011; Yakimov et al., 2013). In spite of their harsh conditions, $16 \mathrm{~S}$ rRNA gene sequencing surveys indicate that abundant and diverse microbial life has adapted to these extreme environments. Several uncultured groups were first observed in DHAB microbial diversity studies, including the bacterial Candidate Division KB1, the archaeal Mediterranean Seafloor Brine Lake Group 1 (MSBL-1), and other 'MSBL' groups within the Phylum Proteobacteria. Since these uncultured, presumably halophilic groups mostly lack genomic analysis (see Mwirichia et al., 2016 for a recent exception), their physiology and survival strategies have not been described (Antunes et al., 2011). 
High-salinity environments are particularly challenging to microorganisms because biological membranes are sensitive to osmotic pressure, requiring cells to maintain a cytoplasmic solute concentration higher than that of the surrounding brine in order to prevent water loss. There are two known strategies microorganisms use to prevent dehydration: the "salt in" strategy, where organisms actively pump salt into the cell (usually $\mathrm{K}^{+}$and $\mathrm{Cl}^{-}$) and the contrasting "salt out" strategy, where organisms produce compatible organic solutes or transport them into the cytoplasm (Oren, 2008). It is also possible to utilize a combination of strategies (e.g., Lai and Gunsalus, 1992). Microorganisms that predominantly use the "salt in" strategy also require special enzymatic adaptations, namely a higher proportion of acidic amino acids and a lower proportion of hydrophobic amino acids. This same bias prevents normal enzymatic function at lower salinities and, therefore, "salt in" strategists have been documented to be specialists and true halophiles. On the other hand, organisms predominantly using the "salt out" strategy produce and/or import organic-compatible solutes that do not require special intracellular protein adaptations (Oren, 2008). Compatible solute production or transport can be regulated by the cell, allowing "salt out" strategists to live at a range of salinities. However, compatible solute production is more energetically costly than maintaining high intracellular salt concentrations (Oren, 1999).

Of particular interest are the Candidate Division KB1 bacteria, commonly found in high-salinity anoxic environments. KB1 was initially detected by $16 \mathrm{~S}$ rRNA gene sequencing from the Kebrit Deep brine basin in the Red Sea (Eder et al., 1999). The uncultured KB1 bacteria were proposed to be responsible for assimilation of glycine betaine as carbon substrate. Enrichments from Mediterranean seafloor brines (Lake Médée) contained a mixed microbial community that predominately yielded 16S rRNA sequences associated with KB1 and the archaeal halophile MSBL1. The enrichment incorporated high concentrations of ${ }^{14} \mathrm{C}$-labeled glycine betaine, which resulted in increased concentrations of trimethylamine in the media, suggesting possible cleavage of glycine betaine into acetate and trimethylamine (Yakimov et al., 2013).

Here we report the phylogeography of KB1, its phylogenetic relationships to Candidate Division OP1 Bacteria, and its potential metabolic roles and osmotic stress strategies based on a partial single cell amplified genome (SAG) from Orca Basin, the largest hypersaline seafloor brine basin in the Gulf of Mexico (Shokes et al., 1977; Pilcher and Blumstein, 2007). Our results support the hypothesis that KB1 in Orca Basin has adapted its proteins to elevated salinity consistent with a "salt in" strategy; its genome also encodes an uptake system for glycine betaine, which might be used not just for osmoregulation but also possibly as a carbon and energy source.

\section{MATERIALS AND METHODS}

\section{Sample Collection and Processing}

Brine samples from the ca. $200 \mathrm{~m}$ thick brine layer in the southern Orca Basin were collected in April 2012 onboard the R/V Pelican (Expedition PE12-22) at Orca Basin (Latitude 26.54.67 N, Longitude 91.21.65 W, 2410 mbsf) with Niskin bottles attached to a rosette sampler equipped with a CTD. Brine was transferred to an argon-flushed sterile canning jar and aliquoted into an $\mathrm{N}_{2}$-flushed sterile stoppered serum vial. The brine sample was stored at $4^{\circ} \mathrm{C}$ and sent to the Bigelow Single Cell Genomics Center (East Boothbay, Boothbay, ME, USA). The sample was processed for single cell sorting followed by multiple displacement amplification of cellular DNA and PCR screening of bacterial 16S rRNA genes (Martinez-Garcia et al., 2012; Stepanauskas, 2012). A cell identified as belonging to the KB1 group by $16 \mathrm{~S}$ rRNA gene screening was selected for further genome amplification and sequencing.

\section{Genome Analysis}

The assembled genome was uploaded and analyzed with the RAST (Aziz et al., 2008) and IMG/ER (Markowitz et al., 2012) annotation servers. Selected putative protein-encoding genes were further investigated by BLASTP searching the NCBI nonredundant protein database (Altschul et al., 1990). Protein sequences were also acquired for comparison through Uniprot ${ }^{1}$ and RAST (Aziz et al., 2008). Amino acids were aligned using MUSCLE (Edgar, 2004). The model selection tool was utilized in MEGA6 and trees were constructed with the maximum likelihood method (Tamura et al., 2013). Neighbor Joining trees (in Supplementary Material) were constructed using a Poisson correction with 1000 bootstrap replicates using MEGA6 (Tamura et al., 2013). Theoretical average protein isoelectric point analysis was performed by importing putative protein encoding genes from RAST into ExPASy's Compute PI/Mw tool ${ }^{2}$. GC profiles were determined and plotted as described previously (Gao and Zhang, 2006).

\section{S rRNA Phylogenetic Analysis}

Sequences classified as KB1 (which includes both the KB1 and OP1 Candidate Divisions) in the SILVA non-redundant database (ver. 119) (Pruesse et al., 2007) were analyzed with the ARB phylogenetic software package (Ludwig et al., 2004) using RaxML maximum likelihood (Stamatakis, 2006).

\section{Database Access}

The SAG sequence is available in RAST (Genome ID 6666666.48888) and IMG/ER (IMG genome ID 2654588133).

\section{RESULTS AND DISCUSSION}

\section{Cell Sorting and Identification}

A total of 32 single cells from the Orca Basin brine sample yielded bacterial 16S rRNA gene amplicons. 16 cells represented the KB1 group, 13 were identified as Deltaproteobacteria, 2 were assigned to the candidate phylum OD1 (Elshahed et al., 2005) and one to the Bacteroidetes phylum. These taxa were also observed in a Sanger 16S rRNA gene clone library from a previous research

\footnotetext{
${ }^{1}$ http://www.uniprot.org

${ }^{2}$ http://web.expasy.org/compute_pi/
} 
collection (Supplementary Figure S1). The KB1-associated SAG with the lowest $\mathrm{Cp}$ value $(5: 08 \mathrm{~h})$, indicating the time the multiple displacement amplification reaches half-maximum fluorescence, was selected for genome sequencing.

\section{Phylogenetics and Phylogeography of KB1}

Conflicting taxonomic classification schemes have obscured the phylogenetic status of KB1 and the related OP1. The major taxonomic classifiers within SILVA (Ref 119) have assigned all $\mathrm{OP} 1$ and KB1-related organisms to one phylum, KB1, and undefined lower-ranking taxonomic categories. On the other hand, Greengenes (ver. 13.8) recently classified OP1 and KB1related sequences into a single phylum, OP1 (McDonald et al., 2012), while maintaining distinct class levels of OP1, KB1, Acetothermia, and MSBL6. Acetothermia has also been suggested as a phylum name for the entire OP1/KB1 complex (Rinke et al., 2013), based on a reconstructed genome obtained from the metagenome of a geothermal acidic stream (Takami et al., 2012).

Our phylogenetic analyses of related sequences from the most recent non-redundant SILVA near-full length 16S rRNA gene database (version 119; Quast et al., 2013) found four distinct phylogenetic groups near the KB1 and OP1 candidate phyla with high $(>80 \%)$ bootstrap statistical support (Figure 1). The single-cell sequences from Orca Basin brine identified as KB1 in the SILVA 119 database formed a monophyletic group with the initial KB1 sequences from the Red Sea Kebrit Deep brine basin (Eder et al., 1999) and with sequences from a wide range of other hypersaline habitats, including high salinity microbial mats, hypersaline lakes, solar salterns, and other deep-sea brine basins (van der Wielen, 2005; Tkavc et al., 2011; Makhdoumi-Kakhki et al., 2012) (Figure 1).

The initial Obsidian Pool sequence OPB14 (AF027045) (Hugenholtz et al., 1998) formed a distinct monophyletic group with sequences from other high-temperature (e.g., NCBI accession EU645931) and hydrocarbon-influenced (e.g., EU542465) environments; this group constitutes the OP1 lineage sensu stricto (Hugenholtz et al., 1998). The uncultured Candidatus taxon Acetothermum autotrophicum, reconstructed by metagenomic analysis from an acidic hot spring community (Takami et al., 2012), belonged to a cluster separate from the Obsidian Pool OP1 clone sequences. This separate, monophyletic cluster includes sequences from both high-temperature and hydrocarbon-impacted environments, and constitutes the Acetothermia sensu stricto (Figure 1).

The fourth monophyletic cluster is termed the Mediterranean Seafloor Brine Lake 6 (MSBL6) group, since it was initially found in 16S rRNA gene sequencing surveys of Mediterranean brine basins (Daffonchio et al., 2006); the original sequence dataset is represented here by Bannock Basin clone DQ289342 (Figure 1). Since then, the MSBL6 lineage has been populated by sequences from hydrocarbon-impacted environments, including cold seeps, sediments near sulfate-methane transition zones, and a methaneinfluenced brackish lake from which a partial single-cell genome [SAG SCGCAAA255-C06] was obtained (Rinke et al., 2013).

\section{Genome Analysis of KB1}

The Orca Basin KB1-classified SAG genome contained 709508 bp and was estimated to be $25 \%$ complete based on the presence of 107 genes identified to be present in $95 \%$ of bacterial genomes in the Comprehensive Microbial Resource database (Dupont et al., 2012; Supplementary Table 1). Sequences for at least 12 tRNAs were found. The GC content was $46.70 \%$ (Supplementary Figure S2). Putative genes were identified for vitamin and cofactor biosynthesis and metabolism, a complete acetyl-CoA (Wood-Ljungdahl) pathway, cell wall biosynthesis, RNA protein metabolism, DNA metabolism and repair, and fatty acid and lipid metabolism. Genes potentially related to oxidative stress response, heat and cold shock response, and glycine betaine transport were also identified (Supplementary Table 2).

\section{Osmotic Regulation}

The osmotic regulation strategy of $\mathrm{KB} 1$ is of particular interest since the KB1 clade contains sequences exclusively from hypersaline environments. KB1 contains genes potentially coding for uptake of compatible solutes such as glycine betaine or proline betaine, and for uptake of $\mathrm{K}^{+}$(Supplementary Table 2), indicating either intracellular accumulation of compatible solutes as a "salt out" strategist, accumulation of potassium salts as a "salt in" strategist, or a combination of both strategies (Oren, 2008).

The distribution of predicted protein isoelectric points in the $\mathrm{KB} 1$ genome suggests that $\mathrm{KB} 1$ is adapted for using the "salt in" strategy (Figure 2). Accumulation of salts, primarily $\mathrm{K}^{+}$, for osmotic regulation was first observed in halophilic archaea in the phylum Halobacteria, and subsequently in the bacterium Salinibacter ruber in the phylum Bacteroidetes (Antón et al., 2002; Mongodin et al., 2005). The predicted proteins inferred from these organisms' genomes contain a higher proportion of acidic amino acids than do proteins from microorganisms that do not accumulate intracellular salts (Mongodin et al., 2005). The isoelectric point distribution of inferred proteins from the KB1 SAG (Figure 2) indicated a preference for proteins with higher abundances of acidic amino acids (30\% pI 5.0), similar to S. ruber, but proportionally fewer acidic amino acids than the extreme archaeal halophile, Halobacterium NCR-1 ( $\sim 2 \%$ pI 4.5). Conversely, $C$. Acetothermum autotrophicum within the Acetothermia, and the partial SAG genome SCGC AAA255-C06 in the MSBL6 clade (Rinke et al., 2013), had protein isoelectric point abundance patterns similar to those of organisms that do not accumulate high concentrations of intracellular salts, including Escherichia coli and Desulfohalobium retbaense, a sulfate-reducing bacterium isolated from the hypersaline Retba Lake (Senegal, West Africa) thought to accumulate compatible solutes as its primary mechanism for osmoregulation (Spring et al., 2010).

Amino acids were further analyzed to determine which acidic amino acids (glutamate or aspartate) were contributing to the isoelectric point pattern in KB1. Analysis of individual amino acid abundances in proteins inferred from ORFs from the Orca Basin KB1 SAG indicated that glutamate was more abundant than aspartate, which was only marginally higher in abundance 


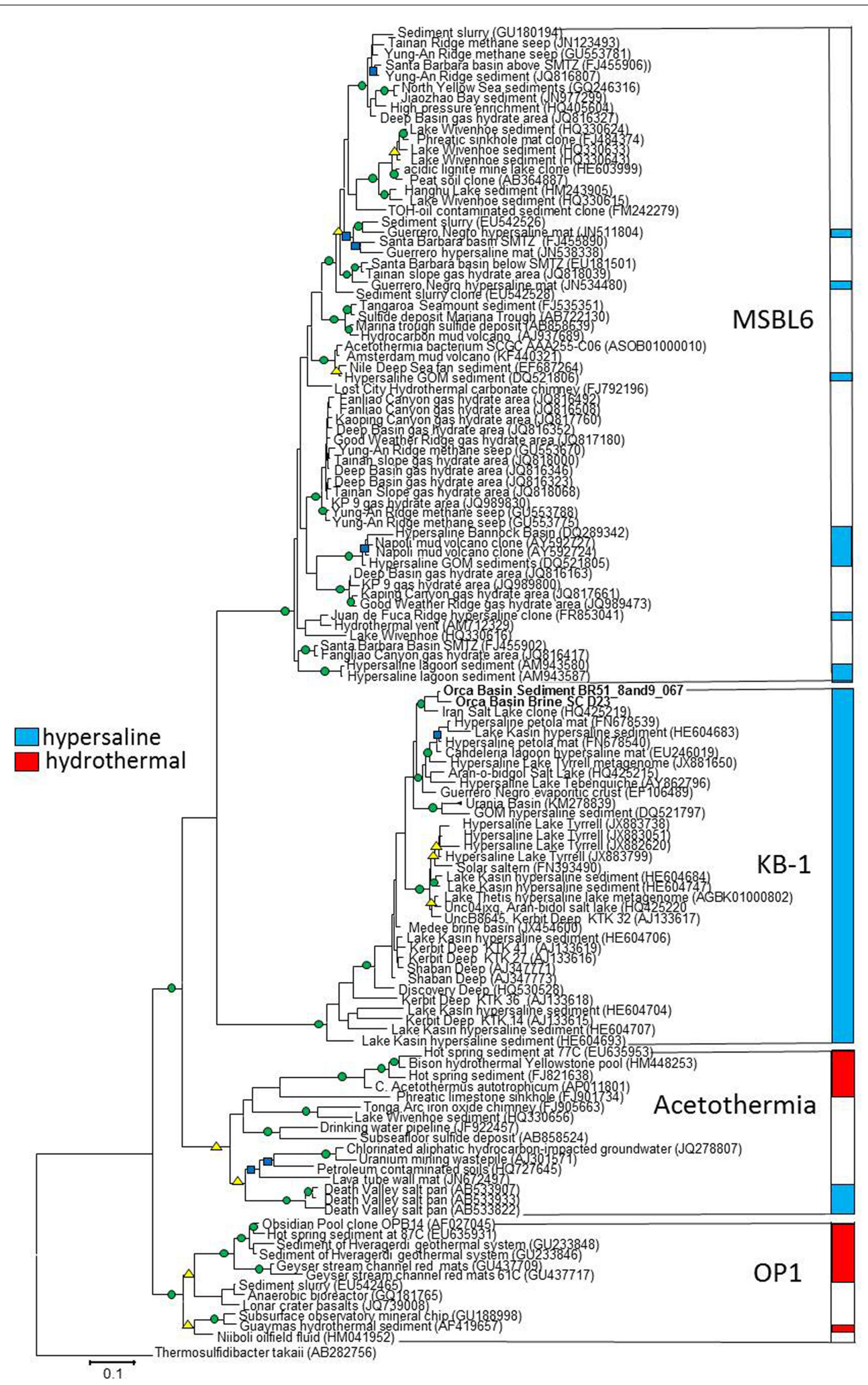

FIGURE 1 | RaxML tree of nearly full-length 16S rRNA genes of Candidate division KB1 and related bacteria. The GTRMix rate distribution model was used with the rapid bootstrap algorithm. Circles indicate bootstrap support of 1000 replicates, green $90-100 \%$, yellow $80-90 \%$ and blue $70-79 \%$. The tree is rooted with the deeply branching bacterium Thermosulfidibacter tokaii, Group names indicate Greengenes Class taxonomy. The scale bar indicates the length of 0.1 nucleotide substitutions per site. 


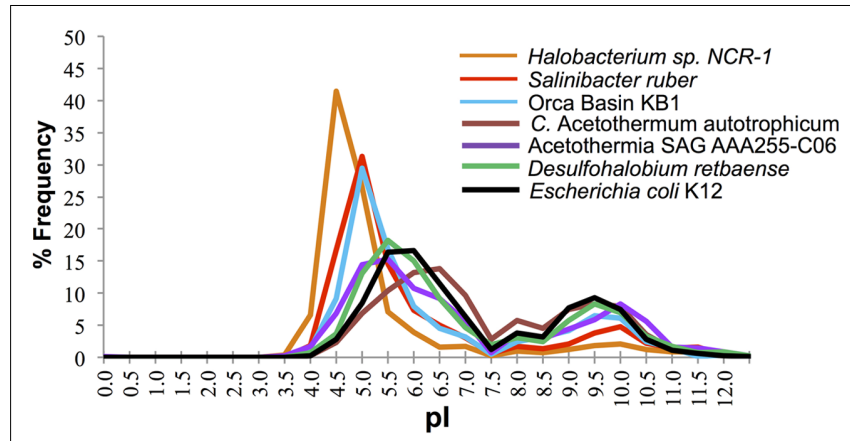

FIGURE 2 | Frequency of predicted isoelectric point (nearest 0.5) of putative proteins in the genomes of the OP1/KB1 phylum complex and other halophilic and non-halophilic bacteria. The plot includes Orca Basin KB1; SAG SCGCAAA255-C06 from a methane and sulfide-rich zone of a brackish lake (Rinke et al., 2013), C. Acetothermum autotrophicum (Takami et al., 2012), Halobacterium NRC-1, a halophilic "salt in" archaeon;

Salinibacter ruber, a "salt in" halophilic bacterium; Desulfohalobium retbaense, a "salt out" halophilic bacterium and Escherichia coli K12.

than in the non-halophilic or "salt out" strategist bacteria analyzed. However, bias for glutamate was not universal among the "salt in" strategists, as Halobacterium contained higher concentrations of aspartate, while $S$. ruber contained elevated acidic amino acids, but near-equal proportions of glutamate and aspartate (Figure 3).

\section{Utilization of Glycine Betaine in KB1}

Glycine betaine is among the most common compatible solutes produced and/or imported by "salt out" strategists in response to osmotic stress. Glycine betaine transport systems can aid cells in maintaining osmotic balance and are well studied in cultured isolates, including non-halophilic Escherichia and Salmonella species which use these specific transport systems to adapt to elevated salinity within non-extreme survival limits (Perroud and Le Rudulier, 1985; Koo and Booth, 1994). Once in the cytoplasm, glycine betaine has several possible fates (Müller et al., 1981; Naumann et al., 1983; Möller et al., 1984; Heijthuijsen and Hansen, 1989; Watkins et al., 2014): it can be retained as a compatible solute, cleaved to acetate and trimethylamine (Naumann et al., 1983; Heijthuijsen and Hansen, 1989), or demethylated to dimethylglycine (Müller et al., 1981; Möller et al., 1984). Demethylation to glycine has been considered the dominant pathway in aerobic bacteria, while cleavage has been considered the dominant anaerobic pathway. However, demethylation does occur in some anaerobes, such as marine sulfate-reducing bacteria (van der Maarel et al., 1996) and marine methanogenic archaea (Watkins et al., 2014). In some methylotrophic methanogenic archaea, demethylation of glycine betaine to dimethylglycine has been observed to be connected directly to methanogenesis (Watkins et al., 2014).

The Orca Basin SAG KB1 contains a compact gene cassette potentially encoding a glycine betaine uptake system, specifically a 3-protein proline or glycine betaine $\mathrm{ABC}$ transporter system,
ProU (genes proVWX) (Supplementary Figure S3). Neighborjoining trees of the ProU proteins (ProV, ProW, ProX; Supplementary Figure S4), and bootstrap analysis of the tree topologies showed that these proteins did not form wellsupported phylogenetic lineages with ProU protein sequences from known organisms. Interestingly, no recognizable glycine betaine uptake genes were observed in the nearly complete OP1related genome of $C$. Acetothermum autotrophicum (Takami et al., 2012), indicating that glycine betaine uptake may not be universal to all members of the KB1 and OP1 clades. However, since the Orca Basin KB1 contains these genes, we propose that glycine betaine utilization starts with importing glycine betaine into the cell via the ATP binding cassette (ProU; T.C. 3.A.1.12.1).

Once glycine betaine is inside the cell, the genes detected near the transporter system suggest different possible fates. One possibility is demethylation and subsequent use of the methyl group as a carbon source via the acetyl-CoA (Wood-Ljungdahl) pathway. Investigating the physiological and phylogenetic diversity of methyltransferases, Ticak et al. (2014) recently provided evidence that a family of corrinoidcontaining trimethylamine methyltransferases related to trimethylamine transferases in the methanogen Methanosarcina spp. demethylate glycine betaine in Desulfitobacterium hafniense Y51. The trimethylamine methyltransferase protein was upregulated during growth of $D$. hafniense on glycine betaine, and spectrophotometric evidence suggested that the recombinant protein converted glycine betaine and cob(l)alamin to dimethylglycine and methylcobalamin. Possibly, one or several putative methyltransferases in KB1 have a similar function (Supplementary Figure S5).

A KB1 methyltransferase (Supplementary Figure S3 and S5) could potentially transfer one of the methyl groups of glycine betaine to tetrahydrofolate, yielding dimethylglycine and 5methyl-tetrahydrofolate. The fate of dimethylglycine remains unknown - no enzymes for dimethylglycine demethylation were found - but potential genes for glycine decarboxylase and sarcosine (N-methylglycine) oxidase were detected, indicating the possibility of complete demethylation to glycine (Supplementary Figure S7). The methylated tetrahydrofolate could possibly enter the methyl branch of the Wood-Ljungdahl pathway (Kreher et al., 2008; Ragsdale and Pierce, 2008), since the necessary enzymes appear to be encoded in the KB1 genome (Supplementary Figures S3 and S5; Supplementary Table 2). The pathway can, therefore, potentially be used in the oxidative direction if an appropriate electron acceptor (e.g., formate) is available and able to be utilized by the organism (Kreher et al., 2008). The carbon monoxide dehydrogenase complex and acetyl-CoA synthase were also detected in the partial KB1 genome. If the redox regime in the Orca Basin brine permits microorganisms to sustain the reductive acetyl-CoA pathway that reduces $\mathrm{CO}_{2}$ with formate or hydrogen, which is consistent with the thoroughly reducing conditions in surficial sediments in Orca Basin (Zhuang et al., 2016), the genomic evidence would allow the interpretation that glycine betaine provides $\mathrm{KB} 1$ with a source of $\mathrm{C} 1$ compounds for biosynthetic purposes (Supplementary Figure S6). Otherwise, KB1 may utilize one of the alternative pathways of glycine 


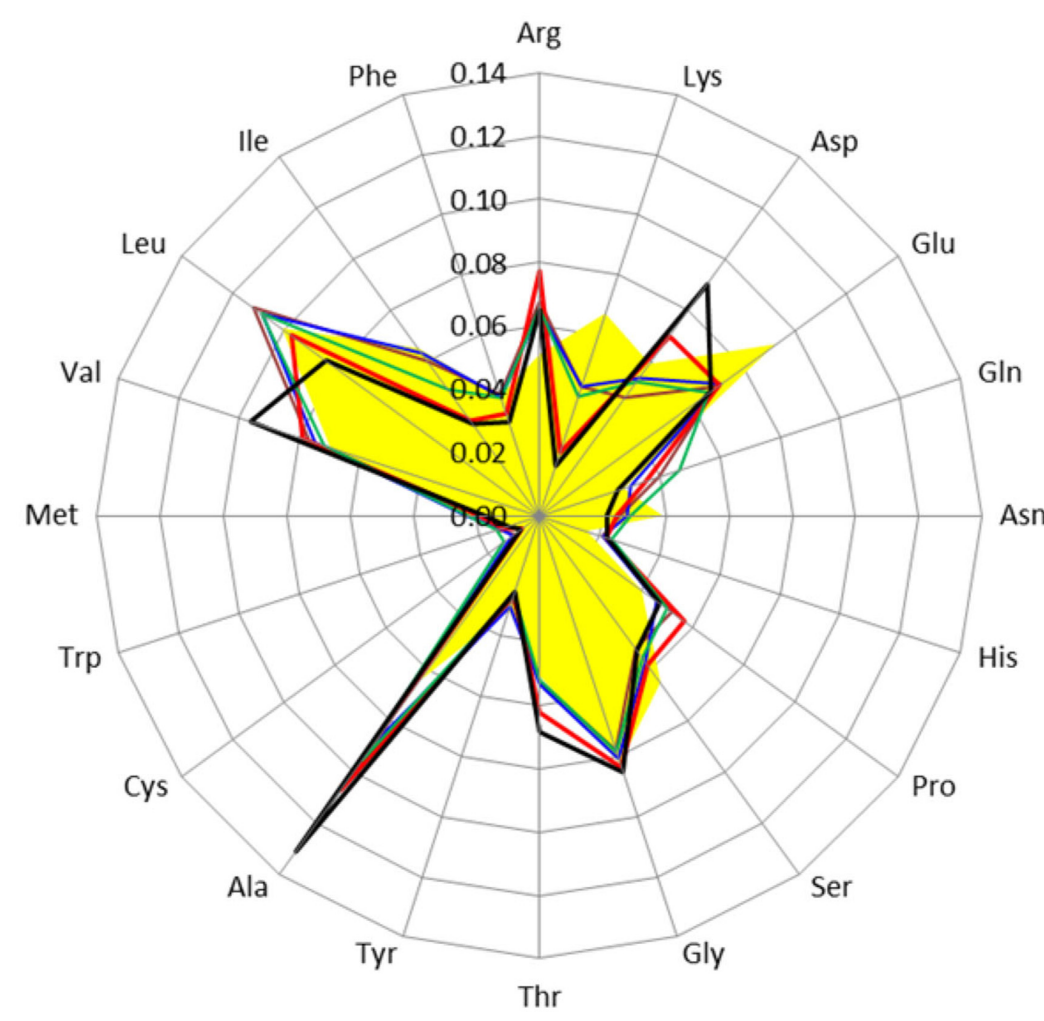

Orca Basin KB1

$\square$ C. Acetothermum autotrophicum

$\square$ Acetothermia SAG AAA255-CO6

口Salinibacter ruber

$\square$ Desulfohalobium retbaense

․ Halobacterium sp.

FIGURE 3 | Frequency of amino acids in putative proteins in the genomes of the OP1/KB1 phylum complex and other halophilic and non-halophilic bacteria. The plot includes Orca Basin KB1; SAG SCGCAAA255-C06 from a methane- and sulfide-rich zone of a brackish lake (Rinke et al., 2013); C. Acetothermum autotrophicum (Takami et al., 2012); Halobacterium NRC-1, a halophilic "salt in" archaeon; Salinibacter ruber, a "salt in" halophilic bacterium; Desulfohalobium retbaense, a "salt out" halophilic bacterium.

betaine catabolism. Yakimov et al. (2013) suggested that KB1 might produce both acetate and trimethylamine, and grow as a syntroph of methylotrophic archaea, following previous results that glycine betaine-metabolizing bacteria can form syntrophic associations with methylotrophic methanogens (e.g., King, 1984). Enrichments dominated by KB1 and MSBL1 $16 S$ rRNA sequences incorporated ${ }^{14} \mathrm{C}$-labeled glycine betaine and produced trimethylamine following glycine betaine addition (Yakimov et al., 2013). MSBL1 were recently proposed to be mixotrophic sugar-fermenting organisms based on single cell genomic analysis (Mwirichia et al., 2016). The cleavage enzyme (glycine betaine reductase) that traditionally produces acetate and trimethylamine was not detected in Orca Basin KB1, but could not be discounted due to the fragmentary SAG. Potentially, KB1 may utilize both demethylation and cleavage of glycine betaine, depending on environmental factors and potential syntrophic relationships.

\section{Phylogenetic Analysis of Acetyl-CoA Pathway Genes and Metabolic Function}

Phylogenetic analysis of the concatenated acetyl-CoA pathway proteins carbon monoxide dehydrogenase (subunit CooS) and the acetyl-CoA synthase (subunit AcsB) indicate monophyly of Orca Basin KB1 with C. Acetothermum autotrophicum
(Figure 4). Complete enzymes of the acetyl-CoA pathway have been recognized in the genome of $C$. Acetothermum autotrophicum within the Acetothermi group (Takami et al., 2012) (Figure 1).

The acetyl-CoA pathway is known to operate in both directions (e.g., Hattori et al., 2005). In C. Acetothermum autotrophicum, it was proposed to function autotrophically by fixing $\mathrm{CO}_{2}$ with $\mathrm{H}_{2}$ (Takami et al., 2012). KB1 may also be able to utilize the pathway to fix $\mathrm{CO}_{2}$ when carbon is scarce. As a further possibility, KB1 may also produce acetyl-CoA, in combination with heterotrophy (Schuchmann and Müller, 2014). Genes encoding the protein subunits of pyruvate:ferredoxin oxidoreductase (EC 1.2.7.1) were also observed in the genome (RAST peg 635-637) indicating another possibility for production of acetyl-CoA utilizing the Wood-Ljungdahl pathway, potentially in combination with methyl groups derived from glycine betaine demethylation (Supplementary Figure S6) (Kreher et al., 2008). Several genes for acetyl-CoA fermentation to butyrate were also present, though not all genes comprising the pathway were observed in the partial KB1 genome (Supplementary Figure S8).

\section{Implications}

The Candidate Division OP1/KB1 bacteria are deeply rooted on the tree of life (Takami et al., 2012). The four distinct 


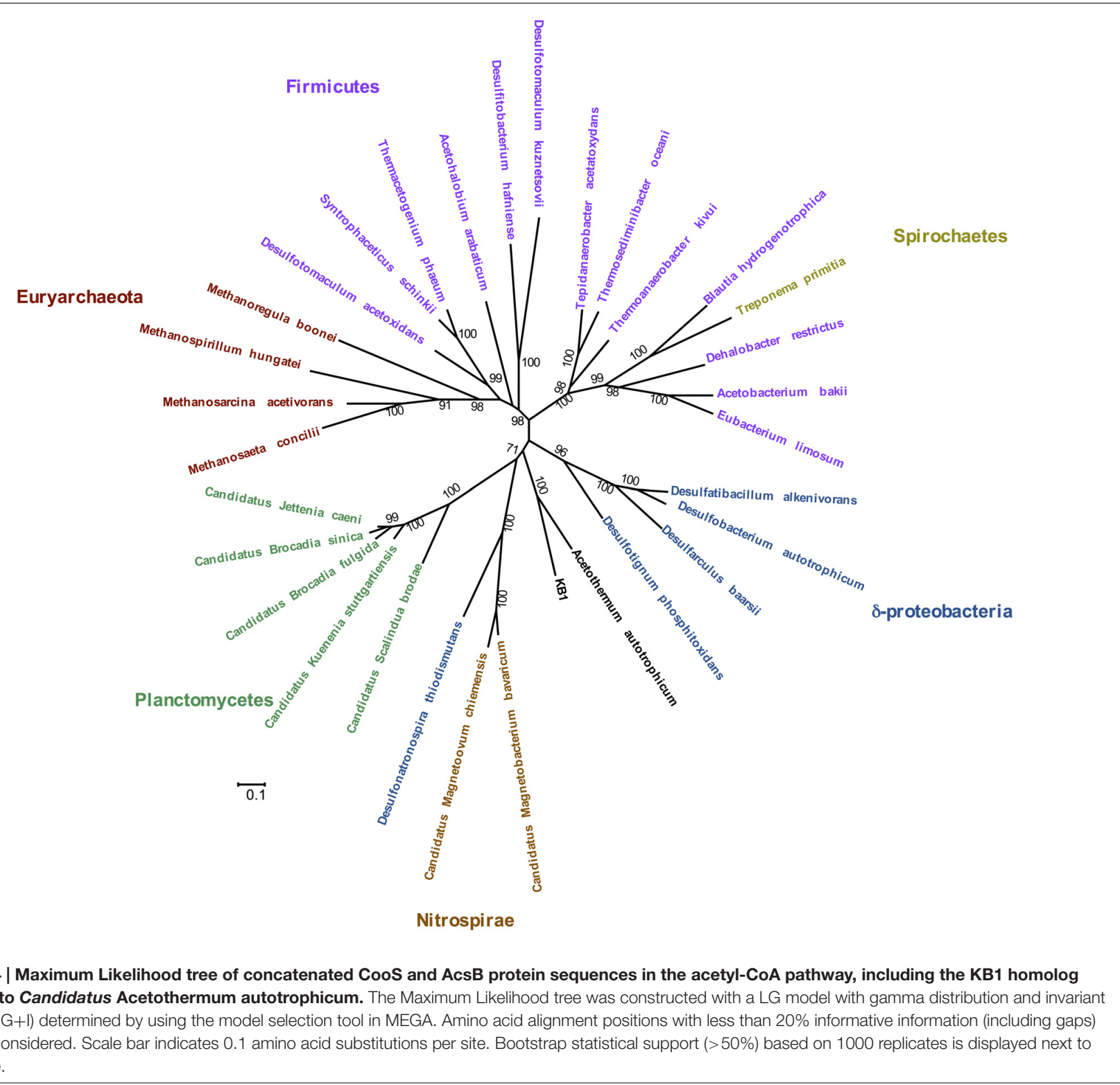

groups of the OP1/KB1 complex (Figure 1) were consistent with class-level taxa according to the Greengenes taxonomic classification. Therefore, it is proposed to retain OP1, KB1, MSBL6, and the Acetothermia as four separate groups on class level which are combined into a single phylum; this conservative solution should be preferable to the alternative of elevating these class-level taxa to four different phyla within a superphylum, analogous to previously proposed cases (Wagner and Horn, 2006). The acidic amino acid bias indicated evolutionary change in KB1 from its common ancestor with OP1, allowing it to thrive under hypersaline conditions, and likely prohibiting it from living at low salt concentration. The acetyl-CoA pathway is potentially orthologous among KB1 and OP1, but glycine betaine uptake proteins and methyltransferases were possibly horizontally transferred. KB1 evolved a unique combination of protein modifications and compatible solute uptake and utilization pathways to survive in hypersaline environments.

\section{AUTHOR CONTRIBUTIONS}

LMN and AT designed the study. LMN and ASH performed the data analysis and constructed the figures. LMN and AT wrote the manuscript. BJM gave critical feedback and contributed to the text as well as the interpretation of results.

\section{FUNDING}

This research was supported by NSF grant MO-MIP No. 0801742 to AT. 


\section{ACKNOWLEDGMENTS}

We thank Mark Pagani and Courtney Warren at Yale University for inviting us to participate on their research expedition (funded by the Yale Climate and Energy Institute and NASA Education as part of the CT Space Grant Consortium), and the crew of RV Pelican for exemplary support in the field during cruise PE12-22. We are also grateful for the excellence and dedication of the staff of the Single Cell Genomics Center at Bigelow Labs, and its Director, Ramunas Stepanauskas, for

\section{REFERENCES}

Altschul, S. F., Gish, W., Miller, W., Myers, E. W., and Lipman, D. J. (1990). Basic local alignment search tool. J. Mol. Biol. 215, 403-410. doi: 10.1016/S00222836(05)80360-2

Antón, J., Oren, A., Benlloch, S., Rodríguez-Valera, F., Amann, R., and RossellóMora, R. (2002). Salinibacter ruber gen. nov., sp. nov., a novel, extremely halophilic member of the Bacteria from saltern crystallizer ponds. Int. J. Syst. Evol. Microbiol. 52, 485-491. doi: 10.1099/00207713-52-2-485

Antunes, A., Ngugi, D. K., and Stingl, U. (2011). Microbiology of the Red Sea (and other) deep-sea anoxic brine lakes. Environ. Microbiol. Rep. 3, 416-433. doi: 10.1111/j.1758-2229.2011.00264.x

Aziz, R. K., Bartels, D., Best, A. A., DeJongh, M., Disz, T., Edwards, R. A., et al. (2008). The RAST Server: rapid annotations using subsystems technology. BMC Genomics 9:75. doi: 10.1186/1471-2164-9-75

Boetius, A., and Joye, S. (2009). Thriving in salt. Science 324, 1523-1525. doi: 10.1126/science.1172979

Daffonchio, D., Borin, S., Brusa, T., Brusetti, L., van der Wielen, P. W. J. J., Bolhuis, H., et al. (2006). Stratified prokaryote network in the oxicanoxic transition of a deep-sea halocline. Nature 440, 203-207. doi: 10.1038 /nature 04418

Dupont, C. L., Rusch, D. B., Yooseph, S., Lombardo, M.-J., Alexander Richter, R., Valas, R., et al. (2012). Genomic insights to SAR86, an abundant and uncultivated marine bacterial lineage. ISME J. 6, 1186-1199. doi: 10.1038/ismej.2011.189

Eder, W., Jahnke, L. L., Schmidt, M., and Huber, R. (2001). Microbial diversity of the brine-seawater interface of the Kebrit Deep, Red Sea, studied via 16S rRNA gene sequences and cultivation methods. Appl. Environ. Microbiol. 67, 3077-3085.

Eder, W., Ludwig, W., and Huber, R. (1999). Novel 16S rRNA gene sequences retrieved from highly saline brine sediments of Kebrit Deep, Red Sea. Arch. Microbiol. 172, 213-218. doi: 10.1007/s002030050762

Edgar, R. C. (2004). MUSCLE: multiple sequence alignment with high accuracy and high throughput. Nucleic Acids Res. 32, 1792-1797. doi: 10.1093/nar/gkh340

Elshahed, M. S., Najar, F. Z., Aycock, M., Qu, C., Roe, B. A., and Krumholz, L. R. (2005). Metagenomic analysis of the microbial community at Zodletone Spring (Oklahoma): insights into the genome of a member of the novel candidate division OD1. Appl. Environ. Microbiol. 71, 7598-7602. doi: 10.1128/AEM.71.11.7598-7602.2005

Gao, F., and Zhang, C.-T. (2006). GC-Profile: a web-based tool for visualizing and analyzing the variation of GC content in genomic sequences. Nucleic Acids Res. 34, W686-W691. doi: 10.1093/nar/gkl040

Hattori, S., Galushko, A. S., Kamagata, Y., and Schink, B. (2005). Operation of the CO dehydrogenase/acetyl coenzyme A pathway in both acetate oxidation and acetate formation by the syntrophically acetate-oxidizing bacterium Thermacetogenium phaeum. J. Bacteriol. 187, 3471-3476. doi: 10.1128/JB.187.10.3471-3476.2005

Heijthuijsen, J. H. F. G., and Hansen, T. A. (1989). Betaine fermentation and oxidation by marine Desulfuromonas strains. Appl. Environ. Microbiol. 55, 965-969.

Hugenholtz, P., Pitulle, C., Hershberger, K. L., and Pace, N. R. (1998). Novel division level bacterial diversity in a Yellowstone hot spring. J. Bacteriol. 180, $366-376$. running challenging and potentially corrosive brine samples through their cell sorters and pushing the technology to new limits.

\section{SUPPLEMENTARY MATERIAL}

The Supplementary Material for this article can be found online at: http://journal.frontiersin.org/article/10.3389/fmicb. 2016.01266

King, G. M. (1984). Metabolism of trimethylamine, choline, and glycine betaine by sulfate-reducing and methanogenic bacteria in marine sediments. Appl. Environ. Microbiol. 48, 719-725.

Koo, S.-P., and Booth, I. R. (1994). Quantitative analysis of growth stimulation by glycine betaine in Salmonella typhimurium. Microbiology 140, 617-621. doi: 10.1099/00221287-140-3-617

Kreher, S., Schilhabel, A., and Diekert, G. (2008). Enzymes involved in the anoxic utilization of phenyl methyl ethers by Desulfitobacterium hafniense DCB2 and Desulfitobacterium hafniense PCE-S. Arch. Microbiol. 190, 489-495. doi: 10.1007/s00203-008-0400-8

La Cono, V., Smedile, F., Bortoluzzi, G., Arcadi, E., Maimone, G., Messina, E., et al. (2011). Unveiling microbial life in new deep-sea hypersaline Lake Thetis. Part I: prokaryotes and environmental settings. Environ. Microbiol. 13, 2250-2268. doi: 10.1111/j.1462-2920.2011.02478.x

Lai, M. C., and Gunsalus, R. P. (1992). Glycine betaine and potassium ion are the major compatible solutes in the extremely halophilic methanogen Methanohalophilus strain Z7302. J. Bacteriol. 174, 7474-7477.

Ludwig, W., Strunk, O., Westram, R., Richter, L., Meier, H., Buchner, A., et al. (2004). ARB: a software environment for sequence data. Nucleic Acids Res. 32, 1363-1371. doi: 10.1093/nar/gkh293

Makhdoumi-Kakhki, A., Amoozegar, M. A., Kazemi, B., PaiC, L., and Ventosa, A. (2012). Prokaryotic diversity in Aran-Bidgol salt lake, the largest hypersaline playa in iran. Microbes Environ. 27, 87-93. doi: 10.1264/jsme2. ME11267

Markowitz, V. M., Chen, I.-M. A., Palaniappan, K., Chu, K., Szeto, E., Grechkin, Y., et al. (2012). IMG: the integrated microbial genomes database and comparative analysis system. Nucleic Acids Res. 40, D115-D122. doi: 10.1093/nar/gkr 1044

Martinez-Garcia, M., Swan, B. K., Poulton, N. J., Gomez, M. L., Masland, D., Sieracki, M. E., et al. (2012). High-throughput single-cell sequencing identifies photoheterotrophs and chemoautotrophs in freshwater bacterioplankton. ISME J. 6, 113-123. doi: 10.1038/ismej.2011.84

McDonald, D., Price, M. N., Goodrich, J., Nawrocki, E. P., DeSantis, T. Z., Probst, A., et al. (2012). An improved Greengenes taxonomy with explicit ranks for ecological and evolutionary analyses of bacteria and archaea. ISME J. 6, 610-618. doi: 10.1038/ismej.2011.139

Möller, B., Oßmer, R., Howard, B. H., Gottschalk, G., and Hippe, H. (1984). Sporomusa, a new genus of gram-negative anaerobic bacteria including Sporomusa sphaeroides spec. nov. and Sporomusa ovata spec. nov. Arch. Microbiol. 139, 388-396. doi: 10.1007/BF00408385

Mongodin, E. F., Nelson, K. E., Daugherty, S., Deboy, R. T., Wister, J., Khouri, H., et al. (2005). The genome of Salinibacter ruber: convergence and gene exchange among hyperhalophilic bacteria and archaea. Proc. Natl. Acad. Sci. U.S.A. 102, 18147-18152. doi: 10.1073/pnas.0509073102

Müller, E., Fahlbusch, K., Walther, R., and Gottschalk, G. (1981). Formation of N,N-Dimethylglycine, Acetic Acid, and Butyric Acid from Betaine by Eubacterium limosum. Appl. Environ. Microbiol. 42, 439-445.

Mwirichia, R., Alam, I., Rashid, M., Vinu, M., Ba-Alawi, W., Anthony Kamau, A., et al. (2016). Metabolic traits of an uncultured archaeal lineage -MSBL1from brine pools of the Red Sea. Sci. Rep. 6, 19181. doi: 10.1038/srep 19181

Naumann, E., Hippe, H., and Gottschalk, G. (1983). Betaine: new Oxidant in the Stickland Reaction and methanogenesis from betaine and l-Alanine by 
a Clostridium sporogenes-Methanosarcina barkeri coculture. Appl. Environ. Microbiol. 45, 474-483.

Oren, A. (1999). Bioenergetic aspects of halophilism. Microbiol. Mol. Biol. Rev. 63, $334-348$.

Oren, A. (2008). Microbial life at high salt concentrations: phylogenetic and metabolic diversity. Saline Syst. 4:2. doi: 10.1186/1746-1448-4-2

Perroud, B., and Le Rudulier, D. (1985). Glycine betaine transport in Escherichia coli: osmotic modulation. J. Bacteriol. 61, 393-401.

Pilcher, R. S., and Blumstein, R. D. (2007). Brine volume and salt dissolution rates in Orca Basin, northeast Gulf of Mexico. AAPG Bull. 91, 823-833. doi: $10.1306 / 12180606049$

Pruesse, E., Quast, C., Knittel, K., Fuchs, B. M., Ludwig, W., Peplies, J., et al. (2007). SILVA: a comprehensive online resource for quality checked and aligned ribosomal RNA sequence data compatible with ARB. Nucleic Acids Res. 35, 7188-7196. doi: 10.1093/nar/gkm864

Quast, C., Pruesse, E., Yilmaz, P., Gerken, J., Schweer, T., Yarza, P., et al. (2013). The SILVA ribosomal RNA gene database project: improved data processing and web-based tools. Nucleic Acids Res. 41, D590-D596. doi: 10.1093/nar/ gks1219

Ragsdale, S. W., and Pierce, E. (2008). Acetogenesis and the Wood-Ljungdahl pathway of $\mathrm{CO} 2$ fixation. Biochim. Biophys. 1784, 1873-1898. doi: 10.1016/j.bbapap.2008.08.012

Rinke, C., Schwientek, P., Sczyrba, A., Ivanova, N. N., Anderson, I. J., Cheng, J.-F., et al. (2013). Insights into the phylogeny and coding potential of microbial dark matter. Nature 499, 431-437. doi: 10.1038/nature12352

Schuchmann, K., and Müller, V. (2014). Autotrophy at the thermodynamic limit of life: a model for energy conservation in acetogenic bacteria. Nat. Rev. Microbiol. 12, 809-821. doi: 10.1038/nrmicro3365

Shokes, R. F., Trabant, P. K., Presley, B. J., and Reid, D. F. (1977). Anoxic, hypersaline basin in the Northern Gulf of Mexico. Science 196, 1443-1446.

Spring, S., Nolan, M., Lapidus, A., Glavina Del Rio, T., Copeland, A., Tice, H., et al. (2010). Complete genome sequence of Desulfohalobium retbaense type strain (HR100T). Stand. Genomic Sci. 2, 38-48. doi: 10.4056/sigs. 581048

Stamatakis, A. (2006). RAxML-VI-HPC: maximum likelihood-based phylogenetic analyses with thousands of taxa and mixed models. Bioinformatics 22, 26882690. doi: 10.1093/bioinformatics/btl446

Stepanauskas, R. (2012). Single cell genomics: an individual look at microbes. Curr. Opin. Microbiol. 15, 613-620. doi: 10.1016/j.mib.2012. 09.001

Takami, H., Noguchi, H., Takaki, Y., Uchiyama, I., Toyoda, A., Nishi, S., et al. (2012). a deeply branching thermophilic bacterium with an ancient acetylCoA pathway dominates a subsurface ecosystem. PLoS ONE 7:e30559. doi: 10.1371/journal.pone.0030559
Tamura, K., Stecher, G., Peterson, D., Filipski, A., and Kumar, S. (2013). MEGA6: molecular evolutionary genetics analysis version 6.0. Mol. Biol. Evol. 30, 27252729. doi: 10.1093/molbev/mst197

Ticak, T., Kountz, D. J., Girosky, K. E., Krzycki, J. A., and Ferguson, D. J. (2014). A nonpyrrolysine member of the widely distributed trimethylamine methyltransferase family is a glycine betaine methyltransferase. Proc. Natl. Acad. Sci. U.S.A. 111, E4668-E4676. doi: 10.1073/pnas.1409 642111

Tkavc, R., Gostinčar, C., Turk, M., Visscher, P. T., Oren, A., and GundeCimerman, N. (2011). Bacterial communities in the "petola" microbial mat from the Sečovlje salterns (Slovenia). FEMS Microbiol. Ecol. 75, 48-62. doi: 10.1111/j.1574-6941.2010.00985.x

van der Maarel, M. J., Jansen, M., Haanstra, R., Meijer, W. G., and Hansen, T. A. (1996). Demethylation of dimethylsulfoniopropionate to 3-Smethylmercaptopropionate by marine sulfate-reducing bacteria. Appl. Environ. Microbiol. 62, 3978-3984.

van der Wielen, P. W. J. J. (2005). The enigma of prokaryotic life in deep hypersaline anoxic basins. Science 307, 121-123. doi: 10.1126/science. 1103569

Wagner, M., and Horn, M. (2006). The Planctomycetes, Verrucomicrobia, Chlamydiae and sister phyla comprise a superphylum with biotechnological and medical relevance. Curr. Opin. Biotechnol. 17, 241-249.

Watkins, A. J., Roussel, E. G., Parkes, R. J., and Sass, H. (2014). Glycine Betaine as a direct substrate for Methanogens (Methanococcoides spp.). Appl. Environ. Microbiol. 80, 289-293. doi: 10.1128/AEM.03076-13

Yakimov, M. M., La Cono, V., Slepak, V. Z., La Spada, G., Arcadi, E., Messina, E., et al. (2013). Microbial life in the Lake Medeé, the largest deep-sea salt-saturated formation. Sci. Rep. 3:3554. doi: 10.1038/Srep03554

Zhuang, G., Elling, F., Nigro, L. M., Samarkin, V., Joye, S. B., Teske, A., et al. (2016). Multiple evidence for methylotrophic methanogenesis as the dominant methanogenic pathway in hypersaline sediments from the Orca Basin, Gulf of Mexico. Geochim. Cosmochim. Acta 187, 1-20. doi: 10.1016/j.gca.2016. 05.005

Conflict of Interest Statement: The authors declare that the research was conducted in the absence of any commercial or financial relationships that could be construed as a potential conflict of interest.

Copyright (c) 2016 Nigro, Hyde, MacGregor and Teske. This is an open-access article distributed under the terms of the Creative Commons Attribution License (CC BY). The use, distribution or reproduction in other forums is permitted, provided the original author(s) or licensor are credited and that the original publication in this journal is cited, in accordance with accepted academic practice. No use, distribution or reproduction is permitted which does not comply with these terms. 